\title{
Influence of Different Interfaces on Synchrony During Pressure Support Ventilation in a Pediatric Setting: A Bench Study
}

\author{
Giorgio Conti MD, Cesare Gregoretti MD, Giorgia Spinazzola MD, Olimpia Festa MD, \\ Giuliano Ferrone MD, Flora Cipriani MD, Marco Rossi MD, \\ Marco Piastra MD, and Roberta Costa MD
}

\begin{abstract}
BACKGROUND: In adults and children, patient-ventilator synchrony is strongly dependent on both the ventilator settings and interface used in applying positive pressure to the airway. The aim of this bench study was to determine whether different interfaces and ventilator settings may influence patient-ventilator interaction in pediatric models of normal and mixed obstructive and restrictive respiratory conditions. METHODS: A test lung, connected to a pediatric mannequin using different interfaces (endotracheal tube [ETT], face mask, and helmet), was ventilated in pressure support ventilation mode testing 2 ventilator settings (pressurization time $\left[\text { Time }_{\text {press }}\right]_{50 \%} /$ cycling-off flow threshold $\left[\mathrm{Tr}_{\text {exp }}\right]_{25 \%}$, Time press80\% $_{\text {exp60\% }}$, randomly applied. The test lung was set to simulate one pediatric patient with a healthy respiratory system and another with a mixed obstructive and restricted respiratory condition, at different breathing frequencies (f) $(30,40$, and 50 breaths/min). We measured inspiratory trigger delay, pressurization time, expiratory trigger delay, and time of synchrony. RESULTS: At each breathing frequency, the helmet showed the longest inspiratory trigger delay compared with the ETT and face mask. At $f_{30}$, the ETT had a reduced $T_{\text {press }}$. The helmet had the shortest $T_{\text {press }}$ in the simulated child with a mixed obstructive and restricted respiratory condition, at $\mathbf{f}_{40}$ during $T i m e e_{\text {press50\% }} / \operatorname{Tr}_{\text {exp25\% }}$ and at $\mathbf{f}_{50}$ during Time ${ }_{\text {press80\% }} / \mathrm{Tr}_{\text {exp60\% }}$. In the simulated child with a normal respiratory condition, the ETT presented the shortest $T_{\text {press }}$ value at $f_{50}$ during Time press80\% $/ \mathbf{T r}_{\text {exp60\% }}$. Concerning the expiratory trigger delay, the helmet showed the best interaction at $f_{30}$, but the worst at $f_{40}$ and at $f_{50}$. The helmet showed the shortest time of synchrony during all ventilator settings. CONCLUSIONS: The choice of the interface can influence patient-ventilator synchrony in a pediatric model breathing at increased $f$, thus making it more difficult to set the ventilator, particularly during noninvasive ventilation. The helmet demonstrated the worst interaction, suggesting that the face mask should be considered as the first choice for delivering noninvasive ventilation in a pediatric model. Key words: noninvasive ventilation; patient-ventilator interaction; pressure-support ventilation; endotracheal tube; helmet; face mask. [Respir Care 2015;60(4):498-507. @ 2015 Daedalus Enterprises]
\end{abstract}

\section{Introduction}

The role of noninvasive ventilation (NIV) in children with acute respiratory failure is well known. ${ }^{1-10}$ Several

Drs Conti, Spinazzola, Festa, Ferrone, Cipriani, Rossi, Piastra, and Costa are affiliated with the Institute of Anesthesiology and Intensive Care and Pediatric ICU, Policlinico A Gemelli, Catholic University, Rome, Italy; Dr Gregoretti is affiliated with the Post Anesthesia Care Unit, Pain Service, M Adelaide Hospital, Emergency and Intensive Care, Turin, Italy.

The authors have disclosed no conflicts of interest. studies have described the effectiveness of NIV in pediatric patients affected by exacerbation of chronic respiratory failure, due to restrictive chest wall deformities and neuromuscular diseases, ${ }^{3,4}$ as well as in children with pneu-

\footnotetext{
Correspondence: Olimpia Festa MD, Institute of Anesthesiology and Intensive Care and Pediatric ICU, Policlinico A Gemelli, Catholic University, Largo Francesco Vito 1, 00168 Rome, Italy. E-mail: olimpia. mp.festa@gmail.com.
}

DOI: $10.4187 /$ respcare.03309 


\section{Synchrony During PSV in a Pediatric Setting}

monia, ${ }^{5,6}$ pulmonary edema, ${ }^{7}$ cystic fibrosis, ${ }^{8}$ and status asthmaticus. ${ }^{9,10}$

NIV is usually delivered to pediatric patients during the acute phase in pressure support ventilation (PSV) with different interfaces such as a face mask and, in the past several years, a helmet. Compared with adults, children have a relatively higher breathing frequency, which can adversely affect patient-ventilator synchrony during PSV.11,12 However, ventilator settings and interfaces used affect patient-ventilator synchrony in both cases. ${ }^{13}$

Although neurally adjusted ventilatory assist (NAVA) has been proposed as a partial ventilatory support mode to improve patient-ventilator synchrony, ${ }^{11,14,15}$ its use has been limited by the elevated cost of the catheter and need for specific equipment. Therefore, PSV still remains, in most adult and pediatric ICUs, the accepted standard for delivering partial ventilatory support during invasive and noninvasive ventilation.

Both the use of a comfortable interface to improve patient comfort and appropriate ventilator settings, to optimize patient-ventilator interaction, are needed to increase the tolerance of NIV application. However, few studies have investigated the role of different interfaces on patient-ventilator interaction in children.

The aim of this bench study was to determine whether different interfaces and ventilator settings may influence patient-ventilator interaction (using the simulator as a patient) in pediatric models of normal and mixed obstructive and restrictive respiratory conditions.

\section{Methods}

\section{Study Protocol}

The Respiratory Mechanics Laboratory of Catholic University (Rome, Italy) carried out this study.

An active test lung (ASL 5000, Ingmar Medical, Pittsburgh, Pennsylvania) was connected to a pediatric mannequin through 3 different interfaces: an endotracheal tube (ETT, size $6 \mathrm{~mm}$ inner diameter, Covidien, Mansfield, Massachusetts), a face mask (Koo Medical Equipment, Alpharetta, Georgia), and a helmet (CaStar, Mirandola, Italy). The ETT and the face mask were connected to the ventilator using a standard circuit, and the helmet was connected to a double circuit. ${ }^{16}$ A standard ICU ventilator ventilated the mannequin (Puritan Bennett 840, Covidien) in PSV, without using the air leak compensation software. PSV was $12 \mathrm{~cm} \mathrm{H}_{2} \mathrm{O}$, and PEEP was $5 \mathrm{~cm} \mathrm{H}_{2} \mathrm{O}$. The inspiratory flow trigger was set at the lowest level to avoid autotriggering. A value of $1.5 \mathrm{~L} / \mathrm{min}$ was set with all interfaces, as air leaks were eliminated during NIV by tightening the soft collar of the helmet to the mannequin's neck or the mask to its face.

\section{QUICK LOOK}

\section{Current knowledge}

Noninvasive ventilation success often comes down to patient comfort, including tolerance of the interface and patient-ventilator synchrony. The higher breathing frequencies in children further complicate synchrony, particularly during pressure-support ventilation.

\section{What this paper contributes to our knowledge}

The patient-ventilator interface influences patient-ventilator synchrony in a pediatric model breathing at an elevated breathing frequency. Synchrony was best using a face mask and worst with the helmet. The face mask should be considered as the first choice for delivering noninvasive ventilation in a pediatric model.

The test lung was set to simulate the following different clinical conditions in a pediatric patient of $25 \mathrm{~kg}$ body weight: (1) normal respiratory condition (compliance $1.2 \mathrm{~mL} / \mathrm{cm} \mathrm{H}_{2} \mathrm{O} / \mathrm{kg}$, airway resistance $5 \mathrm{~cm} \mathrm{H} \mathrm{H}_{2} \mathrm{O} / \mathrm{L} / \mathrm{s}$ ); (2) mixed obstructive and restricted respiratory condition (compliance $0.7 \mathrm{~mL} / \mathrm{cm} \mathrm{H}_{2} \mathrm{O} / \mathrm{kg}$, airway resistance $10 \mathrm{~cm} \mathrm{H}_{2} \mathrm{O} / \mathrm{L} / \mathrm{s}$, inspiratory muscle pressure $10 \mathrm{~cm} \mathrm{H}_{2} \mathrm{O}$ ). The simulator was set to breathe at 3 different breathing frequencies (f, 30-40-50 breaths/min).

During PSV, 2 different combinations of pressurization time (Time press $)$ and cycling-off flow threshold $\left(\operatorname{Tr}_{\text {exp }}\right)$ (ie, Time $_{\text {press } 50 \%} / \mathrm{Tr}_{\exp 25 \%}$, defined as the default setting, and Time $_{\text {press } 80 \%} / \mathrm{Tr}_{\text {exp60\% }}$, defined as fast setting and characterized by fast pressurization time and fast cycling-off flow threshold), were applied in random order. Each test condition lasted $20 \mathrm{~min}$, and the last $5 \mathrm{~min}$ of each trial were recorded for further analysis.

\section{Data Acquisition and Analysis}

Air flow $(\dot{V})$ was measured with a pneumotachograph (Fleish No. 2, Metabo, Epaliges, Switzerland), while airway pressure $\left(\overline{\mathrm{P}}_{\mathrm{aw}}\right)$ was measured by a pressure transducer with a differential pressure of $\pm 100 \mathrm{~cm} \mathrm{H}_{2} \mathrm{O}$ (Digima Clic-1, ICULab system; KleisTek Engineering, Bari, Italy), placed distally from the pneumotachograph.

When the mannequin was ventilated through the endotracheal tube or the face mask, the pneumotachograph and the pressure transducer were positioned at the $\mathrm{Y}$ of the ventilator circuit, whereas, during helmet NIV, the 2 were located at the distal end of the inspiratory limb of the double circuit. ${ }^{16}$

All the signals were acquired, amplified, filtered, and digitized at $100 \mathrm{~Hz}$, then recorded on a dedicated personal 

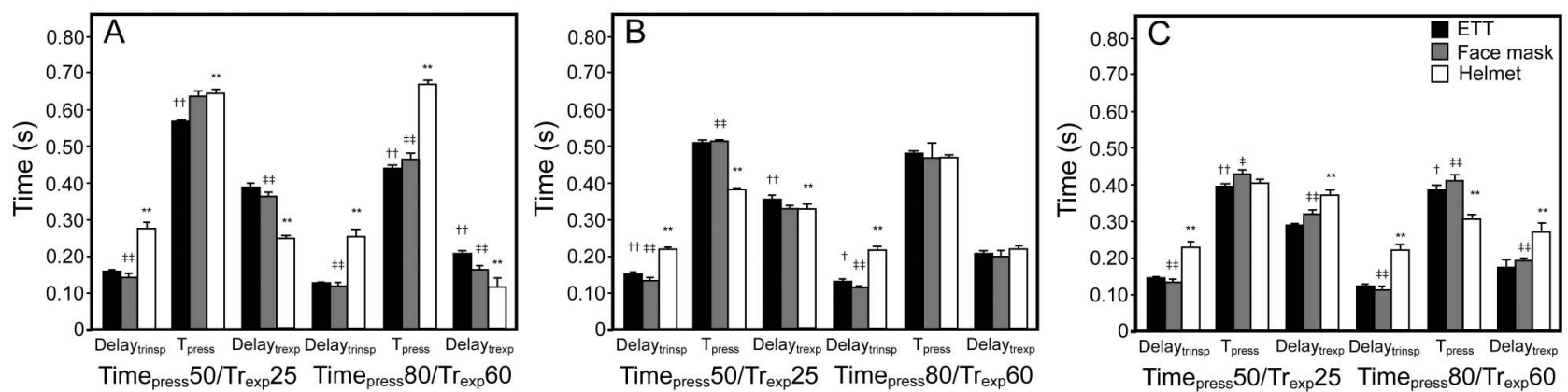

Fig. 1. Inspiratory trigger delay, pressurization time, and expiratory trigger delay with 2 ventilator settings applied at 3 breathing frequencies (30 $[\mathrm{A}], 40[\mathrm{~B}]$, and $50[\mathrm{C}]$ breaths/min), in a pediatric model with mixed obstructive and restricted respiratory condition. Endotracheal tube (ETT, black columns), face mask (dark gray columns), and helmet (white columns). Delay trinsp $=$ inspiratory trigger delay; $\mathrm{T}_{\text {press }}=$ pressurization time; Delay trexp $=$ expiratory trigger delay; Time ${ }_{\text {press }} 50=$ pressurization time of $50 \%$; Time press $80=$ pressurization time of $80 \%$; $\operatorname{Tr}_{\text {exp }} 25=$ cycling-off flow threshold of $25 \% ; \operatorname{Tr}_{\text {exp }} 60=$ cycling-off flow threshold of $60 \% ; \dagger=$ ETT versus face mask; $\ddagger=$ face mask versus

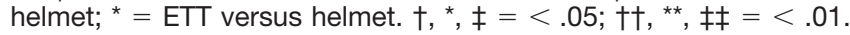

computer, and analyzed through specific software (ICULab 2.7; KleisTek).

Ventilator inspiratory and expiratory time (mechanical $\mathrm{T}_{\mathrm{I}}$ and mechanical $\mathrm{T}_{\mathrm{E}}$, respectively), and ventilator rate of cycling were all determined on the flow tracing. The inspiratory duty cycle (mechanical $\mathrm{T}_{\mathrm{I}} / \mathrm{T}_{\text {tot }}$ ) was calculated as the ratio between mechanical $T_{I}$ and the total mechanical breath duration $\left(\mathrm{T}_{\text {tot }}\right)$.

Air flow and tidal volume $\left(\mathrm{V}_{\mathrm{T}}\right)$ delivered to the simulator, airway opening pressure $\left(\overline{\mathrm{P}}_{\mathrm{aw}}\right)$, and inspiratory muscle effort were displayed online on the computer screen. The signals obtained with the ASL were transmitted to a PC host via 10/100MBit Ethernet, sampled, and processed in real time by means of specific software (Lab View, Ingmar Medical). The signals obtained with the ASL were integrated with the signals from the ICULab system by using a specific application of the ICULab (ICULab 2.7, KleisTek).

The numerical integration of flow over time determined the mechanical tidal volume (mechanical $\mathrm{V}_{\mathrm{T}}$ ). The amount of tidal volume delivered to the simulator during its active inspiration (ie, the neural tidal volume $\left[\mathrm{V}_{\mathrm{T}}\right]$ ) was calculated as the volume generated from the onset of inspiratory muscle effort negative deflection to its nadir.

Interface performance was evaluated using the following parameters: (1) trigger pressure drop $\left(\Delta \mathrm{P}_{\text {trigger }}\right)$, defined as the pressure drop generated during the ventilator triggering; (2) inspiratory pressure-time product (PTP), defined as the area under the $\overline{\mathrm{P}}_{\mathrm{aw}}$ curve relative to the time between inspiratory effort onset and mechanical assistance; (3) pressure-time product at 300 and $500 \mathrm{~ms}\left(\mathrm{PTP}_{300}\right.$ and $\mathrm{PTP}_{500}$ ), defined as the integral $\overline{\mathrm{P}}_{\mathrm{aw}}$ area over insufflation time from simulated effort onset, at 300 or $500 \mathrm{~ms}$, respectively; and (4) PTP $_{500}$ index, expressed as a percentage of ideal PTP, which is unattainable because it would imply a $\Delta \mathrm{P}_{\text {trigger }}$ of zero and an instantaneous pressurization of the ventilator.
Patient-ventilator interaction was evaluated by determining: (1) pressurization time ( $\mathrm{T}_{\text {press }}$ ), defined as the time necessary to achieve the pre-set level of pressure support; (2) inspiratory trigger delay, calculated as the time lag between the onset of inspiratory muscle effort negative swing and the start of the ventilator support (ie, $\overline{\mathrm{P}}_{\mathrm{aw}}$ positive deflection); (3) expiratory trigger delay, assessed as the delay between the end of the inspiratory effort and the end of the mechanical insufflations (ie, flow deflection); (4) time of synchrony, defined as the time during which inspiratory muscle effort and $\overline{\mathrm{P}}_{\mathrm{aw}}$ are in phase (ideally $100 \%$ ); (5) neural $\mathrm{V}_{\mathrm{T}} /$ mechanical $\mathrm{V}_{\mathrm{T}}$, intended as the percentage of $\mathrm{V}_{\mathrm{T}}$ delivered during inspiratory muscle effort negative deflection; (6) wasted efforts, ie, ineffective inspiratory efforts not assisted by the ventilator; and (7) autotriggering, ie, mechanical insufflation in absence of inspiratory effort.

\section{Statistical Analysis}

All data are expressed as mean \pm SD. The analysis of variance for repeated measures was used to detect significant differences between the various experimental conditions. When detected, post hoc analysis was performed using the Bonferroni test; for categorical data, the MantelHaenszel extended chi-square test was used. $P$ values $\leq 0.05$ were considered statistically significant.

\section{Results}

\section{Pediatric Model With a Mixed Obstructive and Restricted Respiratory Condition}

In all tested ventilator settings, the helmet showed the longest inspiratory trigger delay compared with the ETT and face mask $(P<.01)$ (Fig. 1). At $\mathrm{f}_{30}$, with each 

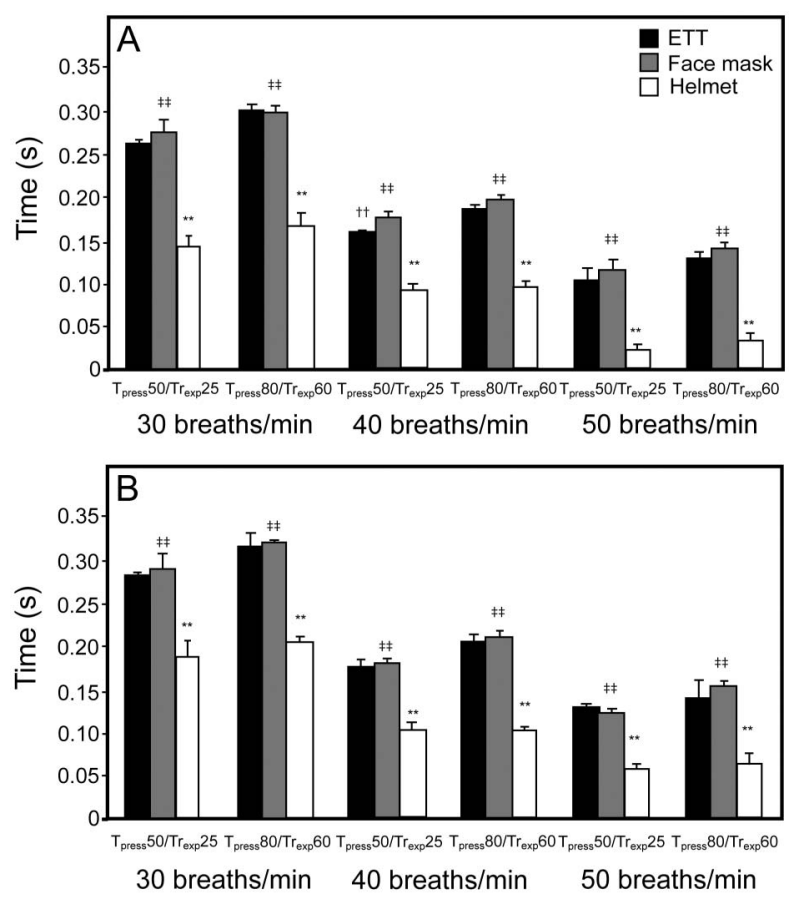

Fig. 2. Time of synchrony with 2 ventilator settings applied at 3 breathing frequencies $(30,40$ and 50 breaths $/ \mathrm{min})$ in a pediatric model with a mixed obstructive and restricted respiratory condition $(A)$ and in a pediatric model with normal respiratory condition (B). ETT - endotracheal tube. $\dagger=$ ETT vs face mask; $\ddagger=$ face mask vs helmet; ${ }^{*}=$ ETT vs helmet. $\dagger,{ }^{*}, \ddagger=<.05 ; \dagger \dagger$,

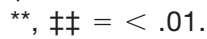

ventilator setting, and at $\mathrm{f}_{50}$ and Time $\mathrm{press}_{50 \%} / \operatorname{Tr}_{\exp 25 \%}$, the ETT had a shorter $\mathrm{T}_{\text {press }}$ than face mask and helmet $(P<.01)$. At $\mathrm{f}_{40}$ at Time $_{\text {press } 50 \%} / \operatorname{Tr}_{\exp 25 \%}$ and at $\mathrm{f}_{50}$ during $\mathrm{Time}_{\text {press80\% }} / \mathrm{Tr}_{\text {exp60\% }}$, the helmet had the shortest $\mathrm{T}_{\text {press }}$ $(P<.01)$.

At $\mathrm{f}_{30}$ during each ventilator setting, the helmet presented the shortest expiratory trigger delay compared with the ETT and face mask $(P<.01)$; at $\mathrm{f}_{40}$, at Time $_{\text {press } 50 \%} / \mathrm{Tr}_{\text {exp25\% }}$, the ETT showed the highest expiratory trigger delay compared with the face mask and helmet $(P<.01)$, whereas no difference was observed during Time $_{\text {press } 80 \%} / \mathrm{Tr}_{\text {exp60\% }}$. At $\mathrm{f}_{50}$, the helmet demonstrated the worst expiratory trigger delay compared with the face mask and ETT $(P<.01)$. The helmet showed the shortest time of synchrony compared with the ETT and face mask at all tested ventilator settings $(P<.01)$ (Fig. 2A).

Mechanical $\mathrm{T}_{\mathrm{I}}$ was significantly affected by ventilator setting, level of simulated $f$ and interface used (Table 1). At $\mathrm{f}_{30}$ and $\mathrm{f}_{40}$, the helmet had a shorter mechanical $\mathrm{T}_{\mathrm{I}}$ than the ETT and face mask $(P<.01)$, whereas at $\mathrm{f}_{50}$, the face mask had the longest mechanical $\mathrm{T}_{\mathrm{I}}$ compared with the ETT and helmet $(P<.05)$.

All interfaces showed a significant decrease of mechanical $\mathrm{V}_{\mathrm{T}}$ when increasing simulated $\mathrm{f}(P<.01)$, irrespective of the ventilator setting. At $\mathrm{f}_{30}$ and $\mathrm{f}_{40}$, the face mask had the highest neural $\mathrm{V}_{\mathrm{T}}$ /mechanical $\mathrm{V}_{\mathrm{T}}$ compared with the ETT and helmet $(P<.01)$. At $\mathrm{f}_{50}$ during Time $_{\text {press50\% }} / \operatorname{Tr}_{\exp 25 \%}$, no difference was found among the tested interfaces, whereas at $\mathrm{Time}_{\text {press } 80 \%} / \operatorname{Tr}_{\text {exp60\%}}$, the helmet showed the lowest neural $\mathrm{V}_{\mathrm{T}}$ /mechanical $\mathrm{V}_{\mathrm{T}}$ $(P<.01)$.

At $\mathrm{f}_{30}$ and $\mathrm{f}_{40}$, the helmet presented the shortest mechanical $\mathrm{T}_{\mathrm{I}} / \mathrm{T}_{\text {tot }}$ compared with the ETT and face mask $(P<.05)$, but at $\mathrm{f}_{50}$, the face mask had a shorter ratio than the other interfaces $(P<.01)$.

Wasted efforts and autotriggering did not occur with any interface or tested ventilator settings.

The helmet had the shortest $\Delta \mathrm{P}_{\text {trigger }}(P<.01)$ (Table 2) and the face mask demonstrated the shortest inspiratory PTP compared with the helmet and ETT $(P<.05)$ at each breathing frequency and ventilator setting. The helmet had the worst performance in terms of $\mathrm{PTP}_{500}$ index at all frequencies and tested settings $(P<.01)$. Conversely, no difference was observed in $\mathrm{PTP}_{500}$ index between ETT and face mask.

\section{Pediatric Model With a Normal Respiratory Condition}

During all tested settings, the helmet had the longest inspiratory trigger delay $(P<.01)$ (Fig. 3). Regarding $\mathrm{T}_{\text {press }}$, at $\mathrm{f}_{30}$, the ETT showed the lowest value $(P<.01)$, whereas at $\mathrm{f}_{40}$, the helmet presented the shortest value $(P<.01)$. At $\mathrm{f}_{50}$, during Time press50\% $/ \mathrm{Tr}_{\exp 25 \%}$, no differences were found between the tested interfaces, but during Time $_{\text {press } 80 \%} / \mathrm{Tr}_{\text {exp60\% }}$, the ETT presented the shortest $\mathrm{T}_{\text {press }}$ value $(P<.01)$.

At $\mathrm{f}_{30}$, the helmet showed the shortest expiratory trigger delay compared with the ETT and face mask $(P<.01)$. Conversely, at $\mathrm{f}_{40}$ and $\mathrm{f}_{50}$, during all conditions, the helmet had the longest expiratory trigger delay value $(P<.01)$. At these frequencies, no difference was found between the ETT and face mask in terms of expiratory trigger delay value.

As in the pediatric model with a mixed obstructive and restricted respiratory condition, the helmet showed the most asynchrony, represented by the shortest time of synchrony $(P<.01)$ (Fig. 2B). No difference has been reported between the time of synchrony with the ETT and face mask.

Increasing frequency and using a rapid pressurization time decreased the mechanical $\mathrm{T}_{\mathrm{I}}$; at $\mathrm{f}_{30}$, the helmet had a shorter mechanical $\mathrm{T}_{\mathrm{I}}$ than ETT and face mask with all tested settings $(P<.01)$ (Table 3). During Time press $50 \% / \operatorname{Tr}_{\exp 25 \%}$, at $\mathrm{f}_{40}$ and $\mathrm{f}_{50}$, no difference was found between the interfaces in terms of mechanical $\mathrm{T}_{\mathrm{I}}$ values. At Time $\mathrm{press80 \%} / \mathrm{Tr}_{\exp 60 \%}$, there were no differences at $f_{40}$, whereas at $f_{50}$, the ETT presented the shortest mechanical $\mathrm{T}_{\mathrm{I}}$ value compared with the other interfaces $(P<.01)$. As observed in the simulated child 


\section{Synchrony During PSV in a Pediatric Setting}

Table 1. Effects of Different Breathing Frequencies and Ventilator Settings on Mechanical Inspiratory Time (Mechanical $\mathrm{T}_{\mathrm{I}}$ ), Mechanical Tidal Volume (Mechanical $\mathrm{V}_{\mathrm{T}}$ ), Percentage of Mechanical Tidal Volume Delivered During Inspiratory Muscle Pressure Negative Deflection (Neural $\mathrm{V}_{\mathrm{T}} /$ Mechanical $\mathrm{V}_{\mathrm{T}}$ ), and Respiratory Pattern (Mechanical $\mathrm{T}_{\mathrm{I}} / \mathrm{T}_{\text {tot }}$ ) with an Endotracheal Tube, Face Mask, and Helmet

\begin{tabular}{|c|c|c|c|c|c|c|c|c|}
\hline \multirow{2}{*}{$\begin{array}{l}\text { Pediatric Model With } \\
\text { Mixed Obstructive } \\
\text { and Restricted } \\
\text { Respiratory Condition }\end{array}$} & \multicolumn{2}{|c|}{$\begin{array}{c}\text { Mechanical } \mathrm{T}_{\mathrm{I}} \\
(\mathrm{s})\end{array}$} & \multicolumn{2}{|c|}{$\begin{array}{c}\text { Mechanical } \mathrm{V}_{\mathrm{T}} \\
(\mathrm{mL})\end{array}$} & \multicolumn{2}{|c|}{$\begin{array}{c}\text { Neural } \mathrm{V}_{\mathrm{T}} / \text { Mechanical } \mathrm{V}_{\mathrm{T}} \\
(\%)\end{array}$} & \multicolumn{2}{|c|}{$\begin{array}{c}\text { Mechanical } \mathrm{T}_{\mathrm{I}} / \mathrm{T}_{\text {tot }} \\
(\%)\end{array}$} \\
\hline & $\begin{array}{c}\text { Time } \\
\operatorname{Tr}_{\text {exp } 25 \%} 50 \%\end{array}$ & $\begin{array}{c}\operatorname{Time}_{\text {press80\% }} / \\
\operatorname{Tr}_{\text {exp60\% }}\end{array}$ & $\begin{array}{c}\operatorname{Time}_{\text {press } 50 \%} / \\
\operatorname{Tr}_{\text {exp25\% }}\end{array}$ & $\underset{\operatorname{Tr}_{\text {exp60\% }}}{\text { Time }_{\text {press80\% }} /}$ & $\begin{array}{c}\text { Time } \\
\operatorname{Tr}_{\text {exp } 25 \%}\end{array}$ & $\begin{array}{c}\operatorname{Time}_{\text {press } 80 \%} / \\
\operatorname{Tr}_{\text {exp60\% }}\end{array}$ & $\begin{array}{c}\operatorname{Time}_{\text {press50\% }} / \\
\operatorname{Tr}_{\text {exp25\% }} /\end{array}$ & $\begin{array}{c}\text { Time } \\
\operatorname{Tr}_{\text {expss } 60 \%} \\
\end{array}$ \\
\hline \multicolumn{9}{|l|}{$\mathrm{f}_{30}$ (breaths/min) } \\
\hline ETT & $0.65 \pm 0.01$ & $0.51 \pm 0.01 *$ & $444 \pm 17 *$ & $421 \pm 5^{*}$ & $51 \pm 0 *$ & $60 \pm 0 *$ & $36 \pm 0$ & $27 \pm 0$ \\
\hline Face Mask & $0.64 \pm 0.01 \dagger$ & $0.46 \pm 0.02 \dagger$ & $396 \pm 10 \dagger$ & $366 \pm 2 \dagger$ & $60 \pm 0 \dagger$ & $70 \pm 0 \dagger$ & $35 \pm 0 \dagger$ & $25 \pm 0 \dagger$ \\
\hline Helmet & $0.39 \pm 0.00 \ddagger$ & $0.28 \pm 0.01 \ddagger$ & $362 \pm 5 \neq$ & $341 \pm 6 \ddagger$ & $47 \pm 0 \S$ & $57 \pm 0 \S$ & $23 \pm 0 \ddagger$ & $17 \pm 0 \ddagger$ \\
\hline \multicolumn{9}{|l|}{$\mathrm{f}_{40}$ (breaths/min) } \\
\hline ETT & $0.52 \pm 0.01$ & $0.40 \pm 0.02$ & $342 \pm 10^{*}$ & $334 \pm 3^{*}$ & $39 \pm 0 *$ & $49 \pm 0 *$ & $39 \pm 0$ & $30 \pm 0$ \\
\hline Face Mask & $0.51 \pm 0.01 \dagger$ & $0.40 \pm 0.02 \dagger$ & $301 \pm 5 \dagger$ & $309 \pm 3$ & $43 \pm 0 \dagger$ & $53 \pm 0 \dagger$ & $39 \pm 0 \|$ & $29 \pm 0 \|$ \\
\hline Helmet & $0.43 \pm 0.01 \ddagger$ & $0.32 \pm 0.01 末$ & $320 \pm 0 \ddagger$ & $309 \pm 0 \ddagger$ & $35 \pm 0 \S$ & $39 \pm 0 \ddagger$ & $34 \pm 0 \S$ & $26 \pm 0 \S$ \\
\hline \multicolumn{9}{|l|}{$\mathrm{f}_{50}$ (breaths/min) } \\
\hline ETT & $0.40 \pm 0.01 \Phi$ & $0.31 \pm 0.01 \Phi$ & $327 \pm 0^{*}$ & $232 \pm 3^{*}$ & $35 \pm 0$ & $49 \pm 0$ & $63 \pm 0^{*}$ & $83 \pm 0^{*}$ \\
\hline Face Mask & $0.44 \pm 0.01 \|$ & $0.33 \pm 0.01 \|$ & $244 \pm 0$ & $254 \pm 3$ & $33 \pm 0$ & $45 \pm 0 \dagger$ & $56 \pm 0 \dagger$ & $77 \pm 0 \dagger$ \\
\hline Helmet & $0.40 \pm 0.00$ & $0.31 \pm 0.01$ & $240 \pm 0 \neq$ & $254 \pm 3 \ddagger$ & $32 \pm 0$ & $33 \pm 0 \ddagger$ & $64 \pm 0$ & $84 \pm 0$ \\
\hline 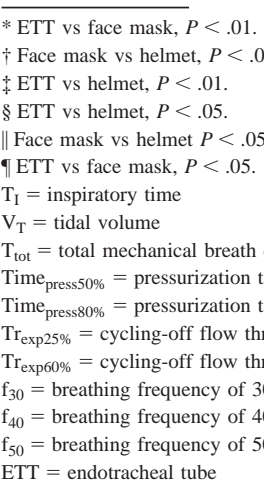 & $\begin{array}{l}\text { Aration } \\
\text { me of } 50 \% \\
\text { me of } 80 \% \\
\text { eshold of } 25 \% \\
\text { eshold of } 60 \% \\
\text { breaths } / \mathrm{min} \\
\text { breaths/min } \\
\text { breaths/min }\end{array}$ & & & & & & & \\
\hline
\end{tabular}

with mixed obstructive and restricted respiratory condition, mechanical $\mathrm{V}_{\mathrm{T}}$ value decreased when increasing the frequency $(P<.01)$, irrespective of the ventilator setting. This was also true during the simulation of the child with normal respiratory condition.

Regarding neural $\mathrm{V}_{\mathrm{T}}$ /mechanical $\mathrm{V}_{\mathrm{T}}$, at $\mathrm{f}_{30}$ and $\mathrm{f}_{40}$, the helmet presented the shortest value compared both to ETT and face mask $(P<.01)$. At $\mathrm{f}_{50}$ during Time $_{\text {press50\% }} / \mathrm{Tr}_{\exp 25 \%}$, no differences were found between the interfaces in terms of neural $\mathrm{V}_{\mathrm{T}}$ /mechanical $\mathrm{V}_{\mathrm{T}}$ values, but during $\mathrm{Time}_{\text {press } 80 \%} / \mathrm{Tr}_{\exp 60 \%}$ the helmet showed a significantly reduced value compared with the ETT and face mask $(P<.01)$.

In terms of mechanical $\mathrm{T}_{\mathrm{I}} / \mathrm{T}_{\text {tot }}$ at $\mathrm{f}_{30}$, the helmet had a lower value compared with the ETT and face mask, whereas at $\mathrm{f}_{50}$, it had the highest value $(P<.01)$. At $\mathrm{f}_{40}$, no difference was found between the tested interfaces.

Wasted efforts and autotriggering did not occur with any interface or tested ventilator settings.

At all frequencies and settings, the helmet showed the shortest $\Delta \mathrm{P}_{\text {trigger }}$ compared with both the ETT and face mask $(P<.01)$ (Table 4$)$. In terms of inspiratory PTP, at $\mathrm{f}_{30}$, no significant difference was observed, whereas at $\mathrm{f}_{40}$ and $\mathrm{f}_{50}$, the helmet had the longest inspiratory PTP value compared with the other interfaces at each setting tested $(P<.01)$. The helmet showed the worst performance, expressed by the shortest $\mathrm{PTP}_{500}$ index $(P<.01)$ at all tested frequencies and settings; no difference in PTP $_{500}$ index was reported between the ETT and face mask.

\section{Discussion}

The main result of this bench study is that the choice of the interface can remarkably influence patient-ventilator synchrony both in a pediatric model with normal respiratory condition and that of mixed obstructive and restricted respiratory condition. To the best of our knowledge, this is the first study aimed at evaluating different interfaces at different rise times, expiratory trigger thresholds, and breathing frequencies in a simulated pediatric patient.

Patient-ventilator synchrony was significantly better 


\section{Synchrony During PSV in a Pediatric Setting}

Table 3. Effects of Different Breathing Frequencies and Ventilator Settings on Mechanical Inspiratory Time (Mechanical $\mathrm{T}_{\mathrm{I}}$ ), Mechanical Tidal Volume (Mechanical $V_{T}$ ), Percentage of Mechanical $V_{T}$ Delivered During Inspiratory Muscle Pressure Negative Deflection $\left(N_{e}\right.$ ural $V_{T} /$ Mechanical $\mathrm{V}_{\mathrm{T}}$ ), and Respiratory Pattern (Mechanical $\mathrm{T}_{\mathrm{I}} / \mathrm{T}_{\text {tot }}$ ) With an Endotracheal Tube, Face Mask, and Helmet

\begin{tabular}{|c|c|c|c|c|c|c|c|c|}
\hline \multirow{2}{*}{$\begin{array}{c}\text { Pediatric Model } \\
\text { With Normal } \\
\text { Respiratory Condition }\end{array}$} & \multicolumn{2}{|c|}{$\underset{(\mathrm{s})}{\text { Mechanical }} \mathrm{T}_{\mathrm{I}}$} & \multicolumn{2}{|c|}{$\underset{(\mathrm{mL})}{\text { Mechanical }} \mathrm{V}_{\mathrm{T}}$} & \multicolumn{2}{|c|}{$\begin{array}{c}\text { Neural } \mathrm{V}_{\mathrm{T}} / \text { Mechanical } \mathrm{V}_{\mathrm{T}} \\
(\%)\end{array}$} & \multicolumn{2}{|c|}{$\begin{array}{c}\text { Mechanical } \\
(\%)\end{array}$} \\
\hline & $\begin{array}{l}\text { Time }_{\text {press } 50 \%} / \\
\operatorname{Tr}_{\text {exp } 25 \%}\end{array}$ & $\underset{\operatorname{Tr}_{\text {exp } 60 \%}}{\operatorname{Time}_{\text {pres } 80 \%} /}$ & $\underset{\operatorname{Time}_{\text {press } 50 \%} /}{\operatorname{Tr}_{\text {exp } 25 \%}}$ & $\underset{\operatorname{Tr}_{\text {exp } 60 \%}}{\operatorname{Time}_{\text {press } 80 \%} /}$ & $\begin{array}{l}\operatorname{Time}_{\text {press } 50 \%} / \\
\operatorname{Tr}_{\exp 25 \%}\end{array}$ & $\begin{array}{l}\text { Time }_{\text {press80\% }} / \\
\operatorname{Tr}_{\text {exp } 60 \%}\end{array}$ & $\begin{array}{l}\text { Time }_{\text {press } 50 \%} / \\
\operatorname{Tr}_{\text {exp } 25 \%}\end{array}$ & $\begin{array}{l}\operatorname{Time}_{\text {press } 80 \%} / \\
\operatorname{Tr}_{\text {exp } 60 \%}\end{array}$ \\
\hline \multicolumn{9}{|l|}{$\mathrm{f}_{30}$ (breaths/min) } \\
\hline ETT & $0.63 \pm 0.01$ & $0.50 \pm 0.01$ & $415 \pm 0$ & $416 \pm 3^{*}$ & $50 \pm 0$ & $62 \pm 0$ & $36 \pm 0$ & $28 \pm 0$ \\
\hline Face mask & $0.68 \pm 0.01 \dagger$ & $0.52 \pm 0.00 \dagger$ & $449 \pm 16$ & $442 \pm 3 \dagger$ & $52 \pm 0 \ddagger$ & $62 \pm 0 \dagger$ & $38 \pm 0 \dagger$ & $28 \pm 0 \dagger$ \\
\hline Helmet & $0.45 \pm 0.01 \S$ & $0.32 \pm 0.02 \S$ & $459 \pm 34$ & $403 \pm 17$ & $46 \pm 0 \|$ & $53 \pm 0 \S$ & $26 \pm 0 \S$ & $19 \pm 0 \S$ \\
\hline \multicolumn{9}{|l|}{$\mathrm{f}_{40}$ (breaths/min) } \\
\hline ETT & $0.50 \pm 0.01$ & $0.41 \pm 0.02$ & $324 \pm 3 \mathbb{I}$ & $333 \pm 8$ & $40 \pm 0$ & $51 \pm 0$ & $38 \pm 0$ & $31 \pm 0$ \\
\hline Face mask & $0.52 \pm 0.01$ & $0.44 \pm 0.01$ & $366 \pm 3 \dagger$ & $357 \pm 3 \dagger$ & $44 \pm 0 \dagger$ & $48 \pm 0 \dagger$ & $40 \pm 0$ & $32 \pm 0$ \\
\hline Helmet & $0.49 \pm 0.01$ & $0.42 \pm 0.01$ & $289 \pm 10 \S$ & $301 \pm 24 \|$ & $33 \pm 0 \S$ & $34 \pm 0 \S$ & $39 \pm 0$ & $34 \pm 0$ \\
\hline \multicolumn{9}{|l|}{$\mathrm{f}_{50}$ (breaths/min) } \\
\hline ETT & $0.45 \pm 0.01$ & $0.33 \pm 0.03 \rrbracket$ & $257 \pm 3$ II & $299 \pm 48$ & $30 \pm 0$ & $55 \pm 0 \mathscr{I}$ & $44 \pm 0$ & $32 \pm 0$ \\
\hline Face mask & $0.46 \pm 0.01$ & $0.38 \pm 0.01 末$ & $274 \pm 3 \dagger$ & $286 \pm 3$ & $28 \pm 0$ & $37 \pm 0 \ddagger$ & $44 \pm 0 \dagger$ & $36 \pm 0 \dagger$ \\
\hline Helmet & $0.46 \pm 0.01$ & $0.41 \pm 0.01 \S$ & $248 \pm 3 \S$ & $241 \pm 1 \|$ & $32 \pm 0$ & $33 \pm 0 \S$ & $48 \pm 0 \S$ & $42 \pm 0 \S$ \\
\hline 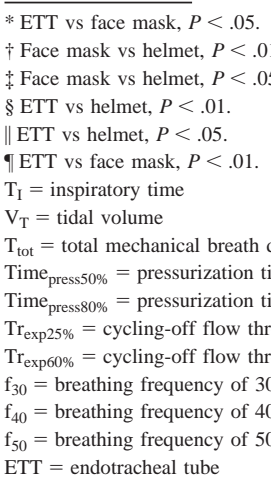 & $\begin{array}{l}\text { uration } \\
\text { me of } 50 \% \\
\text { me of } 80 \% \\
\text { shold of } 25 \% \\
\text { shold of } 60 \% \\
\text { breaths } / \mathrm{min} \\
\text { breaths/min } \\
\text { breaths } / \mathrm{min}\end{array}$ & & & & & & & \\
\hline
\end{tabular}

Interestingly, the progressive increase in frequency produced a trend toward a worsening in patient-ventilator interaction with all the tested interfaces with a significant reduction of the time of synchrony.

In accordance with previous studies, ${ }^{12,13,16-18}$ our results showed that the helmet does not perform as well as the face mask or ETT. Racca et al ${ }^{19}$ demonstrated in 6 healthy volunteers that PSV delivered by a helmet was less effective in unloading the work of breathing compared with a face mask using the same level of support. Their results showed that the mechanical characteristics of the helmet, with its large inner volume and high compliance, could slow the rate of pressurization during mechanical inspiration. Moreover, helmet NIV, compared with face mask, showed an increase in end-inspiratory asynchrony, ${ }^{13}$ thus delaying expiration.

Our results collected in a pediatric model agree with previous results showing that during helmet NIV, mostly at high frequencies, a significant increase of the expiratory trigger delay may be observed compared with the other tested interfaces.
Various strategies have been proposed to minimize helmet drawbacks and optimize its performance, including the choice of specific ventilator settings. ${ }^{13,17,20}$ Vargas et $\mathrm{al}^{20}$ showed that a significant improvement in patientventilator interaction was achieved in adult patients ventilated by a helmet. This was achieved by increasing both PSV and PEEP levels by 50\% and using a high pressurization rate. Costa et al, ${ }^{13}$ evaluating patient-ventilator interaction during PSV delivered with different interfaces (endotracheal tube, face mask and helmet), concluded that an appropriate ventilator setting can significantly improve patient-ventilator interaction during helmet NIV, especially at a high breathing frequency.

In the last several years, many technological efforts have been made to improve interfaces, including helmets. This has involved interface physical characteristics, materials, and design.

Vaschetto et al ${ }^{14}$ tested a new helmet (Next, CaStar) on healthy volunteers. This new device features an opening ring placed underneath an inflatable cushion that secures the helmet without the need for armpit braces. Moreover, 


\section{Synchrony During PSV in a Pediatric Setting}

Table 4. Evaluation of Performance in Terms of Trigger Pressure Drop, Inspiratory Pressure-Time Product, and Percentage of Ideal Pressure-Time Product at $500 \mathrm{~ms}$ With Different Interfaces (Endotracheal Tube, Face Mask, and Helmet) During 2 Ventilator Settings and 3 Different Breathing Frequencies

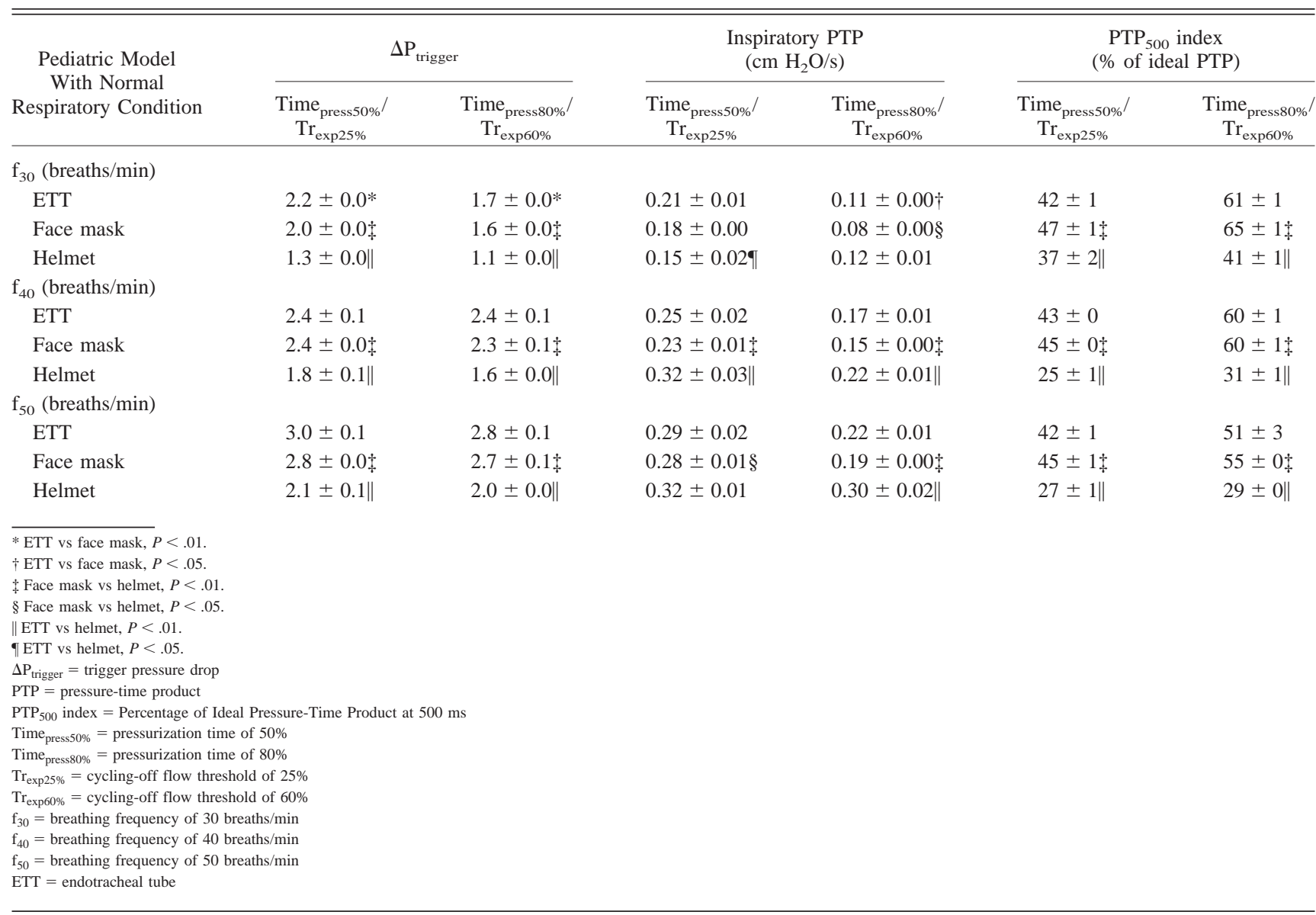

compared with a standard helmet, the Next helmet allows a reduction of pressure dissipation due to the downward displacement of the soft collar during insufflation. The authors showed that the Next helmet significantly improved patient-ventilator interaction compared with a standard type in most of the simulated conditions. The authors concluded that this new interface performs as well as a face mask. These results agree with the findings of another bench study in adults by Olivieri et al, ${ }^{21}$ showing a better performance by the Next helmet during NIV in terms of triggering, patient-ventilator synchrony, and pressurization rate compared with a standard helmet. Unfortunately, this new helmet has not yet been manufactured for pediatric use.

There are few data regarding the role played by the circuit connecting the helmet to the ventilator during NIV. Ferrone et $\mathrm{al}^{16}$ in a bench study compared the use of 2 different circuits (a double tube circuit vs a standard circuit with a Y-piece) for helmet NIV. The authors concluded that a double tube circuit showed significantly better patient-ventilator interaction with shorter inspiratory and expiratory delays, longer time of synchrony, absence of wasted efforts, and better ventilator performance. This suggests that a double circuit (as used in the present bench study) should be preferred in clinical practice.

A mode of partial ventilatory support (NAVA) was proposed to enhance patient-ventilator interaction and to minimize the risk of over- and under-assistance. NAVA delivers mechanical assistance in proportion to patient effort, allowing the tailoring of the mechanical support to patient' respiratory characteristics. Several studies ${ }^{15,22-26}$ showed that NAVA is a safe and reliable mode in the pediatric and infant population. It improved synchrony and patient comfort, reduced ventilator drive, and increased breath-tobreath mechanical variability. Few studies have been performed using proportional assist ventilation in children. ${ }^{27,28}$ Proportional assist ventilation use is limited during NIV due to air leaks hindering its correct functioning.

To date, no study has evaluated the effects of varying the inspiratory rise time and cycling-off criteria during noninvasive PSV in a pediatric population. Our results are in accordance with those reported in adults by Prinianakis et al. ${ }^{29}$ They evaluated the effects of variable pressuriza- 


\section{Synchrony During PSV in a Pediatric Setting}

tion rates on patient's breathing pattern, inspiratory effort, and arterial blood gases in a group of patients with COPD receiving PSV through a face mask. Faster pressurization rates resulted in a reduction of pressure-time product of the diaphragm. This reduction was greater with the fastest rate, but was associated with an increase in air leaks and intolerance.

Our results showed that by using a faster pressurization rate and cycling-off criteria, the performance of all interfaces increased, as demonstrated by the highest value of $\mathrm{PTP}_{500}$ index. Chiumello et al ${ }^{30}$ evaluated the effects of different rise times and cycling-off criteria on breathing patterns and work of breathing in adult patients receiving invasive PSV for acute lung injury. They showed that a shorter inspiratory rise time and longer cycling-off criteria caused an increase in neural $\mathrm{V}_{\mathrm{T}} /$ mechanical $\mathrm{V}_{\mathrm{T}}$.

Further studies are needed to assess the influence of different pressurization rise times and cycling-off criteria during NIV in children. Of note, in adult patients, the choice of interface with appropriate ventilator settings can improve patient-ventilator interaction, as demonstrated when the helmet is used with a fast setting (ie, Time $\left._{\text {press } 80 \%} / \operatorname{Tr}_{\text {exp } 60 \%}\right)^{13}$; however, in pediatric models using higher breathing frequency, a fast setting does not improve patient-ventilator interaction during helmet ventilation.

\section{Limitations of the Study}

The major limitation of the present study is its bench study design. In fact, these results need to be clinically confirmed. However, it is technically and ethically impossible to perform a direct comparison between different interfaces in the same pediatric patient.

\section{Conclusions}

This study suggests that, in a pediatric model receiving NIV, the optimal choice of the interface can be crucial, as it can significantly influence patient-ventilator synchrony. The high breathing frequency, characterizing pediatric breathing pattern, makes it more difficult to set the ventilator, particularly during noninvasive ventilation.

The helmet showed the worst mannequin-ventilator interaction, as demonstrated by the longest inspiratory trigger delay and expiratory trigger delay and shortest time of synchrony, suggesting that the face mask should be considered as the first choice for delivering NIV in a pediatric model.

\section{REFERENCES}

1. Yañez LJ, Yunge M, Emilfork M, Lapadula M, Alcántara A, Fernán$\operatorname{dez} \mathrm{C}$, et al. A prospective, randomized, controlled trial of noninva- sive ventilation in pediatric acute respiratory failure. Pediatr Crit Care Med 2008;9(5):484-489.

2. Hamel DS, Klonin H. The role of noninvasive ventilation for acute respiratory failure. Respir Care Clin N Am 2006;12(3):421-435.

3. Birnkrant DJ, Pope JF, Eiben RM. Pediatric noninvasive nasal ventilation. J Child Neurol 1997;12(4):231-236.

4. Khan Y, Heckmatt JZ, Dubowitz V. Sleep studies and supportive ventilatory treatment in patients with congenital muscle disorders. Arch Dis Child 1996;74(3):195-200.

5. Marino P, Rosa G, Conti G, Cogliati AA. Treatment of acute respiratory failure by prolonged non-invasive ventilation in a child. Can J Anaesth 1997;44(7):727-731.

6. Fortenberry JD, Del Toro J, Jefferson LS, Evey L, Haase D. Management of pediatric acute hypoxemic respiratory insufficiency with bilevel positive pressure (BiPAP) nasal mask ventilation. Chest 1995; 108(4):1059-1064.

7. Akingbola O, Palmisano J, Servant G, Custer J, Moler F. BIPAP(R) mask ventilation in paediatric patients with acute respiratory failure (abstract). Crit Care Med 1994;22(1):A144.

8. Padman R, Lawless S, Von Nessen S. Use of BiPAP by nasal mask in the treatment of respiratory insufficiency in pediatric patients: preliminary investigation. Pediatr Pulmonol 1994;17(2):119-123.

9. Teague WG. Noninvasive ventilation in the pediatric intensive care unit for children with acute respiratory failure. Pediatr Pulmonol 2003;35(6):418-426

10. Thill PJ, McGuire JK, Baden HP, Green TP, Checchia PA. Noninvasive positive-pressure ventilation in children with lower airway obstruction. Pediatr Crit Care Med 2004;5(4):337-342.

11. Bordessoule A, Emeriaud G, Morneau S, Jouvet P, Beck J. Neurally adjusted ventilatory assist improves patient-ventilator interaction in infants as compared with conventional ventilation. Pediatr Res 2012; 72(2):194-202

12. Conti G, Costa R. Technological development in mechanical ventilation. Curr Opin Crit Care 2010;16(1):26-33.

13. Costa R, Navalesi P, Spinazzola G, Ferrone G, Pellegrini A, Cavaliere F, et al. Influence of ventilator settings on patient-ventilator synchrony during pressure support ventilation with different interfaces. Intensive Care Med 2010;36(8):1363-1370.

14. Vaschetto R, Cammarota G, Colombo D, Longhini F, Grossi F, Giovanniello A, et al. Effects of propofol on patient-ventilator synchrony and interaction during pressure support ventilation and neurally adjusted ventilatory assist. Crit Care Med 2014;42(1):74-82.

15. Vignaux L, Grazioli S, Piquilloud L, Bochaton N, Karam O, LevyJamet $\mathrm{Y}$, et al. Patient-ventilator asynchrony during noninvasive pressure support ventilation and neurally adjusted ventilatory assist in infants and children. Pediatr Crit Care Med 2013;14(8):e357-364.

16. Ferrone G, Cipriani F, Spinazzola G, Festa O, Arcangeli A, Proietti $\mathrm{R}$, et al. A bench study of 2 ventilator circuits during helmet noninvasive ventilation. Respir Care 2013;58(9):1474-1481.

17. Costa R, Navalesi P, Antonelli M, Cavaliere F, Craba A, Proietti R, Conti G. Physiologic evaluation of different levels of assistance during noninvasive ventilation delivered through a helmet. Chest 2005;128(4):2984-2990.

18. Navalesi P, Costa R, Ceriana P, Carlucci A, Prinianakis G, Antonelli $\mathrm{M}$, et al. Non-invasive ventilation in chronic obstructive pulmonary disease patients: helmet versus facial mask. Intensive Care Med 2007;33(1):74-81.

19. Racca F, Appendini L, Gregoretti C, Stra E, Patessio A, Donner CF, Ranieri VM. Effectiveness of mask and helmet interfaces to deliver noninvasive ventilation in a human model of resistive breathing. J Appl Physiol 2005;99(4):1262-1271.

20. Vargas F, Thille A, Lyazidi A, Campo FR, Brochard L. Helmet with specific settings versus facemask for noninvasive ventilation. Crit Care Med 2009;37(6):1921-1928. 


\section{Synchrony During PSV in a Pediatric Setting}

21. Olivieri C, Costa R, Spinazzola G, Ferrone G, Longhini F, Cammarota $\mathrm{G}$, et al. Bench comparative evaluation of a new generation and standard helmet for delivering noninvasive ventilation. Intensive Care Med 2013;39(4):734-738.

22. Piastra M, De Luca D, Costa R, Pizza A, De Sanctis R, Marzano L, et al. Neurally adjusted ventilatory assist vs pressure support ventilation in infants recovering from severe acute respiratory distress syndrome: nested study. J Crit Care 2014;29(2):312 e1-5.

23. Breatnach C, Conlon NP, Stack M, Healy M, O'Hare BP. A prospective crossover comparison of neutrally adjusted ventilator assist and pressure-support ventilation in a pediatric and neonatal intensive care unit population. Pediatr Crit Care Med 2010;11(1):711.

24. Beck J, Reilly M, Grasselli G, Mirabella L, Slutsky AS, Dunn MS, Sinderby C. Patient-ventilator interaction during neutrally adjusted ventilator assist in low birth weight infants. Pediatr Res 2009;65(6): 663-668.

25. Alander M, Peltoniemi O, Pokka T, Kontiokari T. Comparison of pressure-, flow-, and NAVA-triggering in pediatric and neonatal ventilatory care. Pediatr Pulmonol 2012;47(1):76-83.
26. Clement KC, Thurman TL, Holt SJ, Heulitt MJ. Neurally triggered breaths reduce trigger delay and improve ventilator response times in ventilated infants with bronchiolitis. Intensive Care Med 2011;37(11): 1826-1832.

27. Schulze A, Rieger-Fackeldey E, Gerhardt T, Claure N, Everett R, Bancalari E. Randomized crossover comparison of proportional assist ventilation and patient-triggered ventilation in extremely low birth weight infants with evolving chronic lung disease. Neonatology 2007;92(1):1-7.

28. Schulze A, Gerhardt T, Musante G, Schaller P, Claure N, Everett R, et al. Proportional assist ventilation in low birth weight infants with acute respiratory disease: a comparison to assist/control and conventional mechanical ventilation. J Pediatr 1999;135(3):339-344.

29. Prinianakis G, Delmastro M, Carlucci A, Ceriana P, Nava S. Effect of varying the pressurization rate during noninvasive pressure support ventilation. Eur Respir J 2004;23(2):314-320.

30. Chiumello D, Pelosi P, Taccone P, Slutsky A, Gattinoni L. Effect of different inspiratory rise time and cycling off criteria during pressure support ventilation in patients recovering from acute lung injury. Crit Care Med 2003;31(11):2604-2610.

This article is approved for Continuing Respiratory Care Education credit. For information and to obtain your CRCE

(free to AARC members) visit 